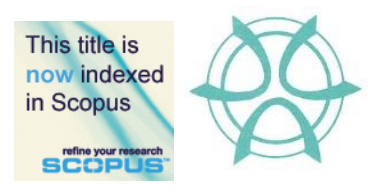

PLANNING MALAYSIA:

Journal of the Malaysian Institute of Planners

VOLUME 15 ISSUE 3 (2017), Page 179 - 192

\title{
AN ANALYSIS OF REGIONAL IMBALANCES IN IRAN: A CASE STUDY OF NORTH COASTAL AREAS
}

\author{
Masoud Taghvaei ${ }^{1}$, Sirous Shafaghi $^{2}, \&$ Mohammadreza Ghaderi $^{3}$ \\ Faculty of Geographical Sciences and Planning \\ UNIVERSITY OF ISFAHAN
}

\begin{abstract}
In countries such as Iran, which cover a large geographical area, the issue of inequality and regional differences provide a substantial challenge in the effort to achieve balanced development. In this study, data were collected using documentary and survey methods as well as Delphi techniques, and analysis was carried out by combining qualitative and quantitative models. In the second step of the Delphi technique, a study of the impact of the factors on each other, and on the regional inequalities of the North coastal area, was made using the crossimpact method. In the final step, the effective factors contributing to the inequalities of the North coastal region were studied using analytical techniques and MicMac software. After analyzing the impact rate of the effective factors on regional imbalances, the key factors were identified and, finally, solutions to reduce the regional imbalances of the North coastal area were proposed.
\end{abstract}

Keyword: Inequality, Region, Regional balance, North Coastal Area

Date Received: $12^{\text {th }}$ April 2017

Date of Acceptance: $11^{\text {th }}$ August 2017 
Masoud Taghvaei, Sirous Shafaghi, \& Mohammadreza Ghaderi

An Analysis of Regional Imbalances in Iran: A Case Study of North Coastal Areas

\section{INTRODUCTION}

Disparities in the provision of goods and services have been the concern of various regional development proponents. Among the issues that need to be addressed by regional initiatives and policies are accessibility and mobility levels between urban and rural populations (Ponrahono et al., 2015).

Despite the wealth of human and natural resources, Iran still suffers from high levels of inequality and poverty, and is one of the developing countries where there are still significant differences between regions. While poverty has decreased in the cities, in the rural areas poverty, unemployment, and inequality are growing. Such regions are increasingly being marginalized from national development. For more than two decades, therefore, policy-makers, urban planners and experts have been focusing on spatial and land use planning, economic development, and growth policies as means to alleviate poverty and minimize inequalities between regions (Ramezani, 1997).

Knowledge of the spatial organization of a region and the factors that cause regional inequalities can lead to an understanding of the policies needed to make development in that region possible. In this study, the capabilities and limitations of the North coastal region in Iran have been identified by studying the spatial organization of this region. After considering the factors that underlie the imbalances, suggestions are proposed as to how these imbalances could be reduced.

\section{RESEARCH BACKGROUND}

Regional imbalances, or regional inequalities, are one of the main problems for policy-makers in many parts of the world, Hence for policy makers, reducing regional disparity may be part of a more general social objective to reduce overall inequality, and in particular inequality between individuals (Dupont, 2007). The problems, which include distribution of income and economic opportunities and activities at both the national and international levels, have continued despite globalization and the ensuing economic growth over the seven decades since the end of World War II. Despite overall growth throughout the world, inequalities still exist, with many areas in underdeveloped countries still suffering from regional imbalances (Petrakos \& Saratsis, 2000). There are a number of perspectives on regional planning, such as the Perroux growth pole theory, which suggests that development is not uniform, or balanced, over an entire region but tends to cluster around a central area or pole. The proponent of this theory believed that macro investments in large urban areas cause the growth of the central areas (Weeler \& Muller, 1986).

In contrast to the growth pole theory, Friedmann divides the spatial system into environment-centre, defining development as a discontinuous and inventive process. Central areas are considered to be organized systems with high developmental capacity while environmental areas are subsystems with any 
development determined by, and dependent on, the central areas (Friedmann, 1972). In other words, in this theory, the centre is considered as the development hub (Clark, 2000). Regional disparities may engender redistributive conflicts, which crowd out good government, but regional and intra-regional disparities are often driven by processes well beyond the responsibility and control of individual regions. Regional disparities may be enhanced by institutions of good governance (e.g. fiscal decentralization) and efficiency-enhancing policies (e.g. trade liberalization), while they may also be amplified by positive outcomes at different spatial scales, such as processes of agglomeration (López-Bazo, Monastiriotis \& Ramos, 2014).

Experiences of regional development vary between countries. For example, in South Korea, regional development problems include urban unilateralism, forgotten rural areas, urban and rural imbalances, uncontrolled migration to urban areas, resource concentration in some areas, urban growth issues, persistent poverty, the entry of multi-national companies, and new colonialism. In China, some of its regional development issues include more participation needed during decision-making processes at the local level of planning, more regional autonomy, and problems in the development process due to international forces (Misra \& Bhooshan, 1981). Also in China, regional differences exist in gross domestic product (GDP), and household real per capita income between urban and rural populations, as well as spatial differences in capital distribution and production efficiency and in human resources (Zhao, 2000). In Scandinavian countries, regional development formed against a backdrop of quick industrial growth in some cities. Whereas, in the Netherlands, there are strong regional differences in productivity between industrial cities, the famous ports and other regions (Eshkevari, 2003).

In Iran, the economy is characterized by development that has led to an uneven spatial pattern of economic activities. The history of regional imbalances in Iran can be traced back to national development plans. The Islamic Revolution in 1979 revealed that the development programs had not been positive for all provinces so that conditions deteriorated in some areas.

Development plans in Iran have frequently been social and economic plans according to higher rules and unfortunately because of the structure of region programs (physical), the spatial program of the plans had no opportunity to be executed. Thus, despite the investments made, the provinces and regions in recent years have not undergone significant changes, resulting in deepening gap between provinces. For example, in two provinces (Sistan Baloochestan and Charmahal Bakhtiari) conditions were worse by the end of the first development program (1989-1993). This was also the case for 15 provinces (East Azerbaijan, West Azerbaijan, Ilam, Tehran, Charmahal Bakhtiari, Khuzestan, Zanjan, Semnan, Qom, Kurdistan, Kerman, Kermanshah, Kohgiluyeh va Boyer-Ahmad, Lorestan, Gilan, Hormozgan, and Hamedan) by the end of the second program 
Masoud Taghvaei, Sirous Shafaghi, \& Mohammadreza Ghaderi

An Analysis of Regional Imbalances in Iran: A Case Study of North Coastal Areas

(1995-1999), and 17 provinces (West Azerbaijan, Isfahan, Ilam, Tehran, Khorasan, Khuzestan, Zanjan, Semnan, Qom, Kurdistan, Kerman, Kermanshah, Kohgiluyeh va Boyer-Ahmad, Lorestan, Gilan, Hormozgan, and Hamedan) by the end of the third program (2000-2004) (Ahmadipour et al., 2007). Thus, the $4^{\text {th }}$ plan, after the revolution (2005 onwards) has shifted its emphasis towards spatial development, and the strengthening of regional and provincial programs in order to reduce regional imbalances.

In the fourth development program, the gap in the development process between the provinces, and its undesirable impacts, forced the government to pay attention to regional imbalances. This led to the creation of executive decentralized institutions and local decision-making in provinces, as well as large-scale investment in industrial and agricultural growth poles in those provinces and regions with sufficient resources. The central provinces of Tehran, Isfahan and Khorasan, and the second rank provinces of Gilan and Kermanshah were considered.

The fifth program also considered regional differences. The new policy for regional development paid more attention to agriculture and investment in undeveloped areas. However, it should be noted that policies for tackling regional differences, in what was an extreme centralist system, were not necessarily successful (Eshkevari, 2003). After taking into consideration the importance of the issue, in this study the factors contributing to the regional imbalances in the North coastal area are identified and analysed, and solutions to reduce the imbalances are proposed.

\section{RESEARCH APPROACH}

Applied developmental research is the method used in the study, and a combination of documentary and survey methods were utilized. Data were gathered through questionnaires and the Delphi technique was used to analyse the data. Questionnaires were completed in two stages by 50 planning and development experts who were in charge of developmental issues. The aim of the research is to recognize and analyse the factors contributing to the imbalances in the North coastal area of Iran. The cross-impact matrix method was then used to analyse data in order to evaluate the impact of factors on each other, and through the use of MICMAC software, the key factors in the creation of regional imbalances were recognized. After enumerating software output and studying matrix compatibility, the obtained variables were considered the most effective factors in this study and the definitive optimal answer to the problem, as well as a basis for evaluating multi-criteria decision-making methods. It should be noted that the direct impact of the key factors has been extracted from the matrix output, as shown in Figure 1 (Godet, Meunier \& Roubel, 2003). 
PLANNING MALAYSIA:

Journal of the Malaysia Institute of Planners (2017)

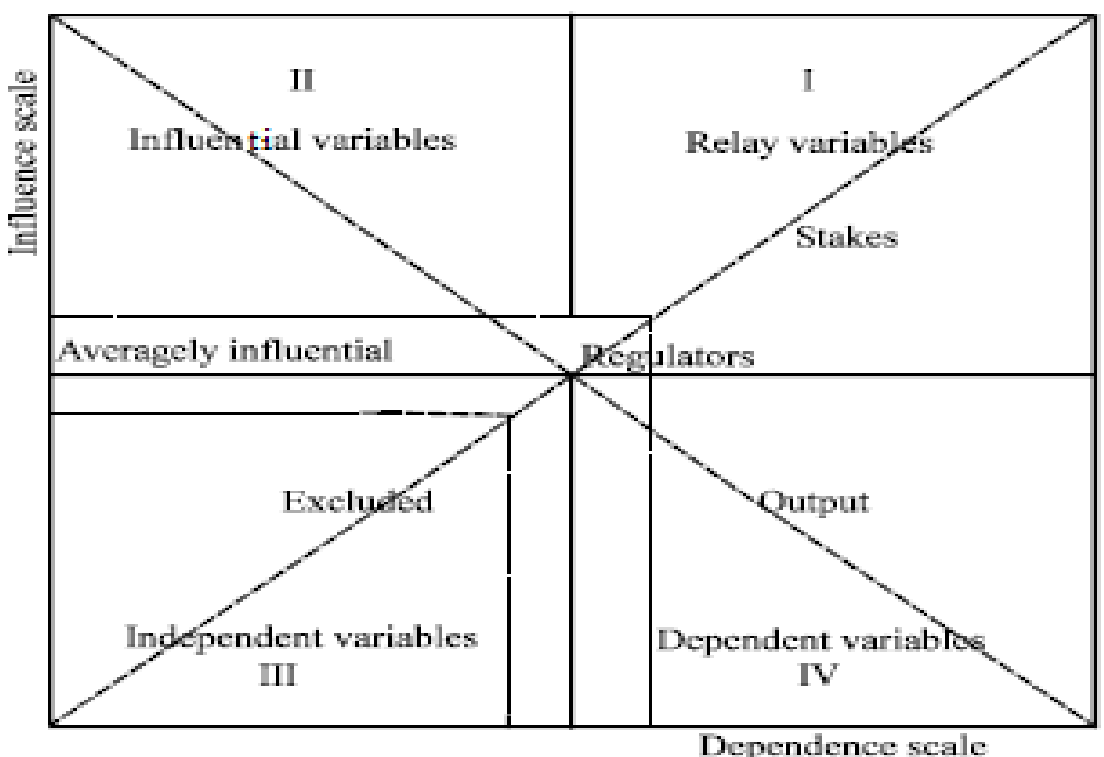

Figure 1 The Status and Conditions of Risk Variables (Key Factors) in the MICMAC Analysis

Source: Hsiu-Yuan Hu, 2009

\section{Background of Study Area}

The study region is located in the North coastal area of the country. This region leads to Turkmenistan from Golestan province. In the south it leads to Semnan, Tehran, Alborz, Qazvin and Zanjan. In the east to North Khorasan, and in the west to the Caspian Sea and Ardabil province. The northern areas are at lower than sea level, and there is an increase in altitude from the east to the south. The position of the North coastal macro-region can be seen in Map 1. The country is divided into nine macro-regions which include 31 provinces. The first macroregion includes North coastal provinces Golestan, Mazandaran and Gilan. 
Masoud Taghvaei, Sirous Shafaghi, \& Mohammadreza Ghaderi

An Analysis of Regional Imbalances in Iran: A Case Study of North Coastal Areas

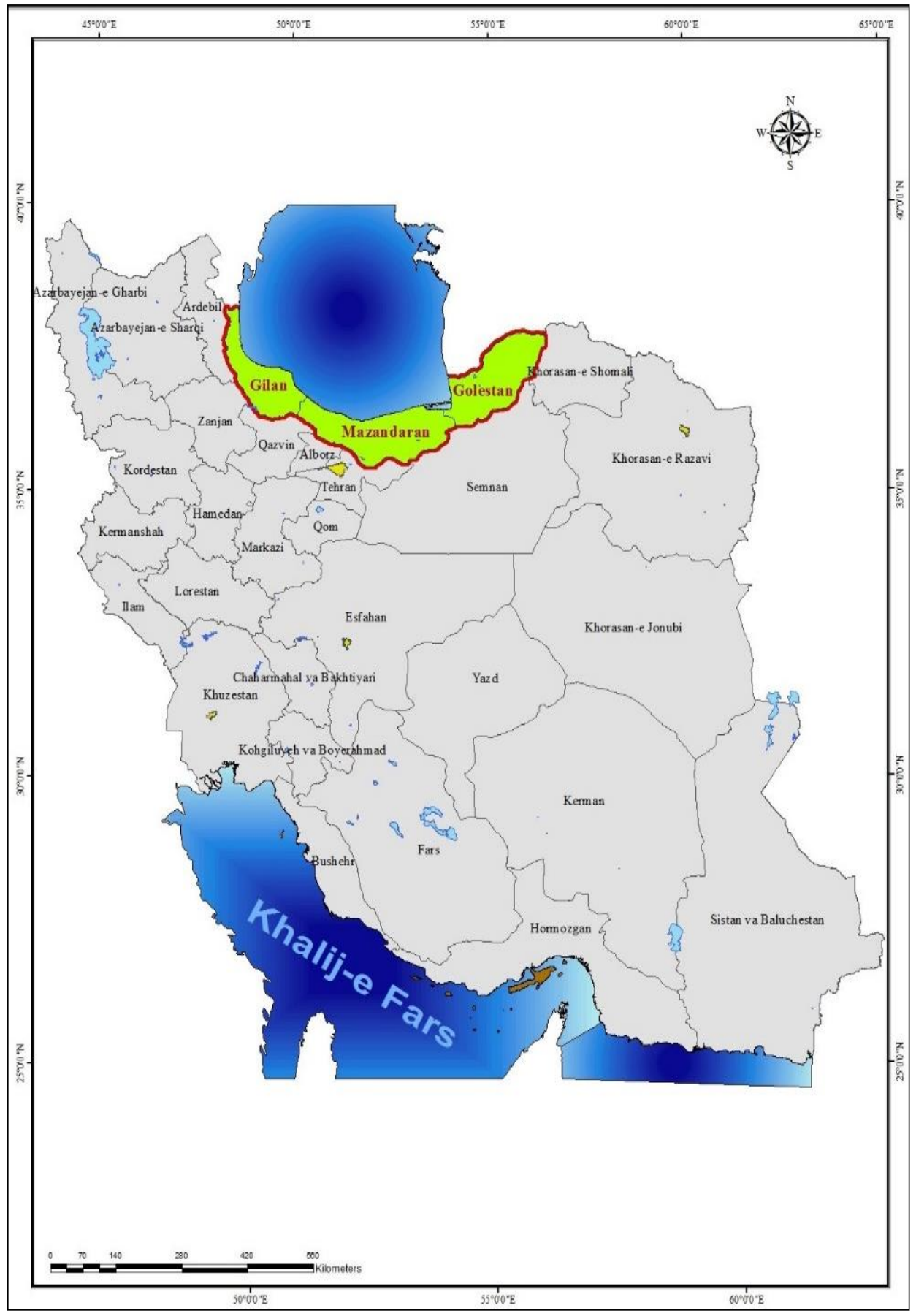

Map 1 The Study Area 


\begin{abstract}
ANALYSIS AND FINDINGS
The North coastal area is one of Iran most unique regions, as in contradictions and contrasts are not as wide as in the other provinces and regions. This region, however, has its own significant imbalances and inequalities, which should be carefully considered due to its importance, sensitivity and roles.

Based the results from the Delphi technique and depending on the type of factors identified in the region, effective factors that are able to address differences, inequalities, and imbalances have been classified as follows.

Environmental and physical indicators: One of the distinguishing characteristics of the North coastal area is that almost all cities, especially the large cities, are located on the coastal plains, and so have easy access to the sea. The proximity (land and sea borders) of the North coastal area to four foreign countries, within 450 kilometres of its coastal borders with the Caspian Sea, has made it possible for this area to have a significant role in commercial transactions, as well as a significant fishing industry. Easy accessibility to the sea has also been an important factor with regard to the area's status as a tourist destination. Therefore, the geographic advantages of the area have likely contributed much to its economic success. However, the natural structure and geography of the area are not without problems - the plains, seashores, and foothills make for an imbalanced settlement system, and also contribute to problems with national and infra-national communication networks (National Physical Planning Studies, 2009).
\end{abstract}

Social, cultural, and human indicators: Analysis of the distribution of residential centres and industrial activities in the North coastal region shows that unplanned growth impacts many valuable environmental zones. The degradation of natural resources and encroachment into protected environmental areas have been well documented, and include issues with agricultural land and forests. Unplanned spatial development and the proximity of the main centres lead to sprawl. This phenomenon, accompanied with overuse, and inefficient use, of land has jeopardized the development of the area (National Physical Planning Studies, 2009).

Management and planning indicators: Instability in the decisionmaking system, including ongoing changes of decision-makers, lack of foresight and inefficient routines are among the most important reasons for uncertainties in these provinces, and which are hindering North coastal region development.

Economic indicators: The rise in spatial inequalities, increasing opportunities in the central regions, and reforms to farmlands have provided the economic motivation for migration of labour. Disparities, on the one hand, and migration, on the other, have caused increased imbalances between central Iran and the surrounding regions. Based on the surveys and available background information, the causes for these regional imbalances were found to originate from 49 factors, which have been categorized into four groups, as in Table 1. 
Masoud Taghvaei, Sirous Shafaghi, \& Mohammadreza Ghaderi

An Analysis of Regional Imbalances in Iran: A Case Study of North Coastal Areas

Table 1 Classification of effective indicators in regional imbalances

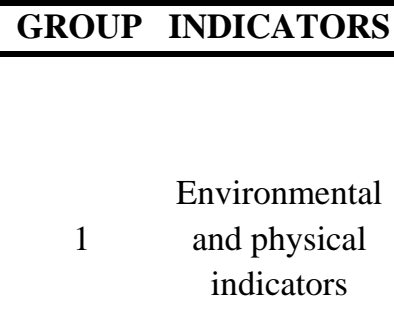

Field proportionality (1), direct access to the sea (2), settlement patterns (3), land use (4), sensitive and valuable ecosystems (5), land constraints (6), physical model of the spatial organization (7), spatial interaction of plains and mountain areas (8), distribution of activities in space (9), activities' adaptability to the capabilities of the environment (10), environmental capabilities (11), topographic diversity (12)

the effects of population density on land resources

Social, cultural, (13), urbanization rate (14), level of services in cities and human (15), ethnic and cultural diversity (16), human indicators development (17), the rate of public participation (18), social welfare (19), immigration (20)

Integrated management development (21), sectoral view on planning (22), resources allocation (23), project-orientedness (24), personal and momentary views on regional development (25), dependence on basic resources (26), polar planning and type of policy planning (27), views on drought and security in and planning peripheral regions (28), borders and peripheral regions

(29), policy effects of outreach documents (30), dependence on oil (31), center-orientedness of services (32), subject-oriented planning (33), spatial sharing

(34), relying on balanced resources (35), ethnic convergence and divergence (36), centralization (37), growth poles (38), single urban system (first city) (39), geographical distribution of resources (40), spatial onedimensional development (41), segregation of sections

(42), industrial trends (43) National policies (44)

Employment range (45), (network economy) interactive relations between areas (46), accumulation

$4 \quad$ Economic of physical investment (47), competitive advantages indicators

(48), interaction of economic operations beyond peripheral regions (49)

Source: The researcher classification. 


\section{DATA ANALYSIS BY MICMAC SOFTWARE}

The factors listed in Table 1 have been identified as the factors contributing to regional imbalances and have been extracted and analysed using MICMAC software. The matrix dimensions are $49 \times 49$, arranged into four groups (Table 1 ).

The matrix $49 \times 49$ filling degree was 88.5 , which shows that the selected factors have a high and disperse impact on each other, and that the system presents an unstable situation.

In Figure 2, the existence of factors with a high degree of effectiveness is low in the top-left of the diagram, since this location has variables in stable systems. Nevertheless, there are several factors near this area which show their considerable impact on the whole system. These variables include "the topographic diversity of the region, dependency on oil through governmental investment, constant and personalized attitudes toward regional development, endogeneity, and reliance on balancing sources". These variables are the most important effective factors in regional imbalances, which play a much higher role in making regional balances or imbalances.

Risk variables are located near the diameter of the south-east area of the diagram and have a very high probability of becoming key system actors. These variables include "sectoral view on planning, polar planning and type of policy planning, center-orientedness of services, policy effects of outreach documents, growth poles, geographical distribution of resources, spatial one-dimensional development, industrial trends". Risk variables can mainly be considered as the variables related to planning and managerial factors.

Target variables are located under the north-east diameter of the plane. These variables are related to how the system could evolve in the future, and indicate the possible targets of a system. By making some changes to these variables, system evolution will be achieved according to plans and targets. The target variables mainly involve the economic variables. It should be noted that the purpose behind promoting the economic variables is to reduce regional imbalances in the North coastal macro-region. These variables include "distribution of activities in space, environmental capabilities, resources allocation, dependence on basic resources, views on drought and security in peripheral regions, Employment range, network economy, accumulation of physical investment, interaction of economic operations beyond peripheral regions". Social issues are given less consideration. In other words, in development planning, the main targets are economic issues, and system efficiency can be achieved through an analysis of the economic issues and by identifying the strength and weakness points. 
Masoud Taghvaei, Sirous Shafaghi, \& Mohammadreza Ghaderi

An Analysis of Regional Imbalances in Iran: A Case Study of North Coastal Areas

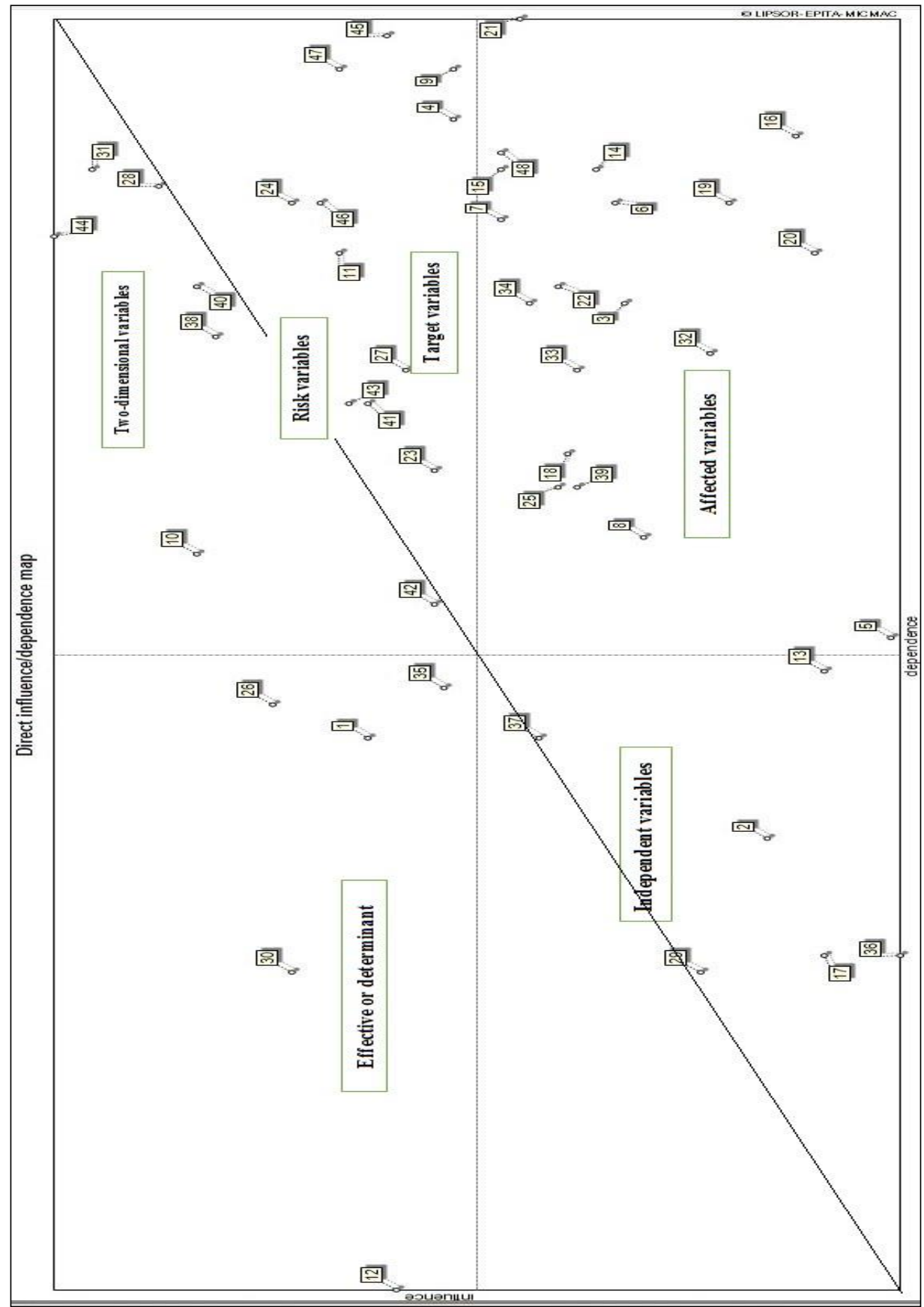

Figure 2. Variable distribution matrix and their locations on the effectivenessimpression axis in the North coastal area Source: MICMAC analysis output. 
The affected variables are located in the south-east area of the diagram and can be called result variables. These variables are strongly affected by the system but have a low-degree of impact on the system. These variables include "center-orientedness of services, field proportionality, settlement patterns, physical model of the spatial organization, spatial interaction of plains and mountain areas, the effects of population density on land resources, level of services in cities, human development, the rate of public participation, social welfare, immigration, integrated management development, projectorientedness, center-orientedness of services, subject-oriented planning, single urban system (first city), competitive advantages".

These indicators are related to improvement of the social situation, social communication, and promotion of the quality of life, which are dimensions on the quality of life index.

Independent variables have low effectiveness and impression. They are located in the south-west of the diagram. Due to the unstable nature of the system, it appears that some of these variables have a system output nature and should be called independent output variables. These variables include "ethnic and cultural diversity, direct access to the sea, sensitive and valuable ecosystems, land constraints, borders and peripheral regions, ethnic convergence and divergence, centralization". Independent variables can be divided into two groups, which are variables independent of the system and variables independent of the system results. The variables of the first group include social and cultural factors and the variables of the second group include environmental issues specific to the North coastal area, such as access to the sea and regional ecosystems plus security issues in the border provinces.

The graph of direct relationships between the variables in Figure 3 show that there are strong relationships between the factors. In overall, the results of the analyses show that risk variables and target variables are the most important factors. 
Masoud Taghvaei, Sirous Shafaghi, \& Mohammadreza Ghaderi

An Analysis of Regional Imbalances in Iran: A Case Study of North Coastal Areas

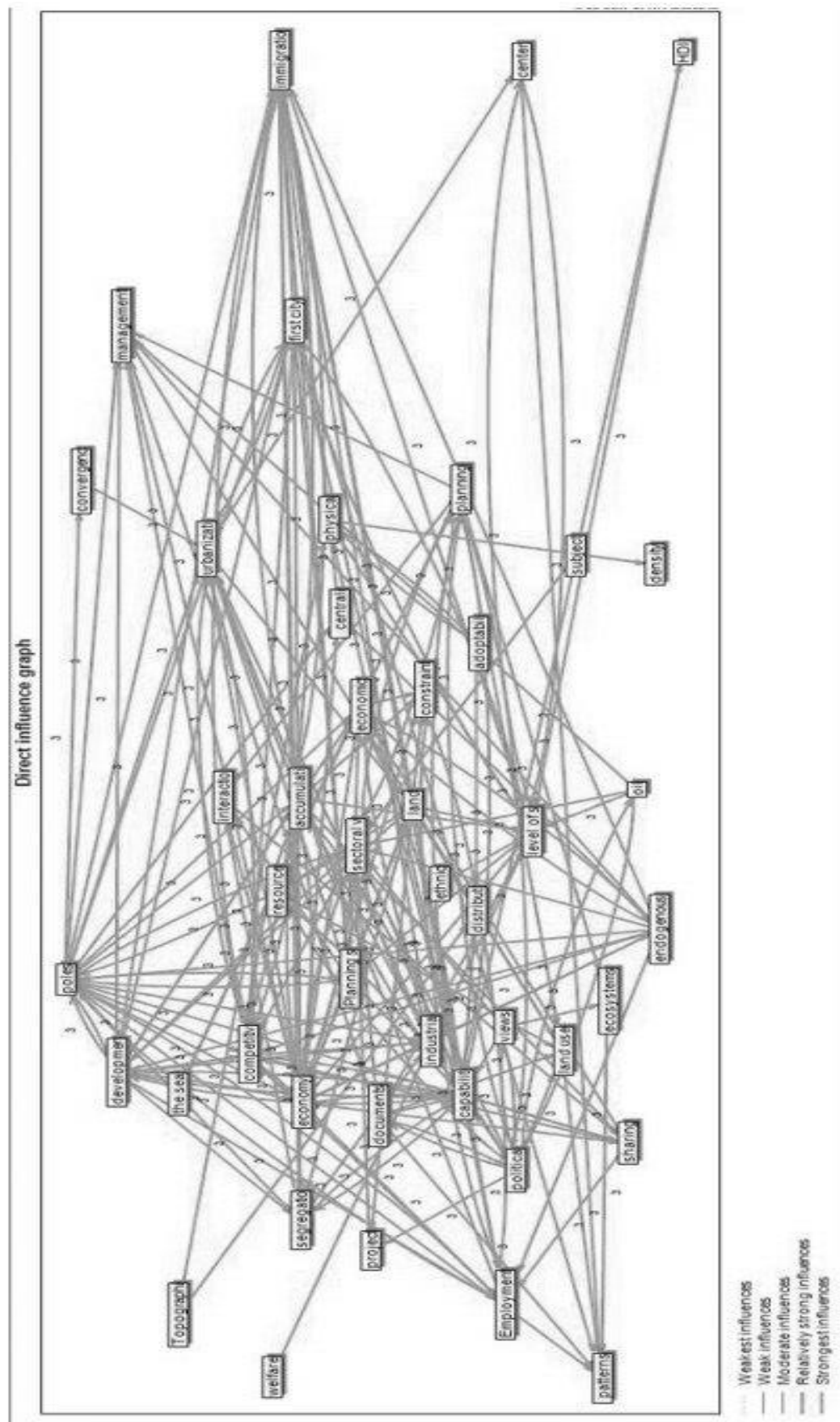

Figure 3. Direct relationships between the variables, the North coastal area Source: MICMAC analysis output. 


\section{DISCUSSION}

The combination of MICMAC output and the Delphi technique revealed the five main factors that contribute to regional imbalances in the study area. These factors are:

Lack of attention to national documents: preparation and implementation of economic development programs, based on sectoral approach and regional attitudes, without considering national documents on the North coastal macro-region, have led to the occurrence and intensification of regional imbalances, the marginalization of some regions, loss of resources and regional capabilities, and land inequalities.

Non-compliance in spatial planning with sectoral planning: as the administrative system in Iran is a sectoral system, the administrative focus has led to most activities being located around the administrative centres, where population density is very high. In addition, sectoral decisions have had uncoordinated land consequences.

The existence of the growth poles: the growth poles of the region have serious problems in terms of resource supplies, environmental protection and efficiency, and continuity of the current development process will lead to further instability and the creation of new imbalances.

The geographical resource distribution system: the budget and distribution of resources in Iran have been based on a sectoral approach and this has had a significant impact on development and in intensifying the regional imbalances between provinces.

Reliance on underground resources: dependency on oil revenue has had the consequence of economic centralization with regard to national income and spending.

Compatibility of activities with the capabilities of the environment: incompatibility between development activities in the North coastal region and the environment is one of the most substantial and important factors with regard to the North coastal region. Environmental capabilities are a potential advantage for the region.

\section{CONCLUSION}

The history of regional planning shows that many challenges need to be overcome in order to achieve desirable regional development. The results of this study demonstrate that current policies and the continuation of existing plans in the North coastal region in Iran will only intensify destruction of the environment, thus increasing imbalances and threatening disorder not only within the region but throughout the whole country. Despite the wide range of investments and financial injections made by the government throughout Iran thus far, including in the North coastal region, it has not been possible to remove the imbalances, mainly because existing agencies in the region are unable to manage the 
Masoud Taghvaei, Sirous Shafaghi, \& Mohammadreza Ghaderi

An Analysis of Regional Imbalances in Iran: A Case Study of North Coastal Areas

developmental mechanisms necessary to resolve the enormous issues that currently exist there. The system demands shrewd management and tools, which do not exist in the structure of the region as it is at present. Thus, to reduce regional imbalances, this study suggests that regional planning in Iran should:

- avoid concentrating development in one centre to the detriment of other areas.

- strengthen international corridors or making new corridors in order to promote the national and trans-national role of regions.

- adopt enhancement and promotion of the spatial development of mountainous areas, using an environmental approach, especially in the western and central regions.

- integrate production systems under experienced management in industry, tourism and business.

- strengthen the functional scale of the regional centres, through commercial performance and accessibility to international corridors. 


\section{ACKNOWLEDGEMENTS}

The authors would like to thank the Professors of Geography and Regional Planning who contributed to the data analysis software MICMAC and for their responses to this study's questionnaire in the development of regional strategies.

\section{REFERENCES}

Ahmadipour, Z., Mokhtari Hashi, H., Roknoddin Eftekhari, R., \& Vazin, N. (2007). The trend of accelerated development of the country's administrative and political spaces: Case study program developed provinces of Iran first to third countries. Geopolitical Quarterly, 3(1), $22-49$.

Clark, D. (2007). Urban World/Global City. London: Routledge.

Dupont, V. (2007). Do geographical agglomeration, growth and equity conflict? Regional Science, 86(2), 193-213.

Eshkevari, S. H. (2003). Analysis of industrial development and regional differences in Iran (Doctorate Thesis). Tehran University, Iran.

Friedmann, J. (1972). A general theory of polarized development. In N. M. Hansen (Ed.), Growth centers in regional economic development, pp. 82-107. London: Macmillan.

Godet, A. J., Meunier, M. F., \& Roubelat, F. (2003). Structural analysis with the MICMAC method \& actors' strategy with MACTOR method. In J. C. Glenn \& T. J. Gordon (Eds.), Futures research methodology, pp. 7-10. AC/UNU Millennium Project.

López-Bazo, E., Monastiriotis V., \& Ramos, R. (2014). Spatial inequalities and economic growth. Spatial Economic Analysis, 9(2), 113-19. Doi: 10.1080/17421772.2014.904615 .

Misra, R. O. \& Bhooshan, B. S. (ZqtZ) (1981). Rural Development. Oxford: Oxford University Press.

National Physical Planning Studies (2009). Volume I, 5-9. Tehran: Budget \& Plan Organization.

Petrakos, G. \& Saratsis, Y. (2000). Regional inequalities in Greece. Regional Science, 79(1), 57-74. Doi: 10.1007/s101100050003.

Ponrahono, Z., Bachok, S., Osman, M. M., Ibrahim, M., Abdullah, M. F., \& Abdullah, A. (2015). Assessing the urban and rural stage bus services disparities in Peninsula Malaysia. Planning Malaysia, 13, 65-84.

Ramezani, M. E. (1997). Measuring the development of North Khorasan regional planning based models (Masters Thesis). Tehran University, Iran.

Weeler, J. O. \& Muller, P. O. (1986). Economic geography. New York: John Wiley \& Sons. 
Masoud Taghvaei, Sirous Shafaghi, \& Mohammadreza Ghaderi

An Analysis of Regional Imbalances in Iran: A Case Study of North Coastal Areas

Zhao, Y. (2000). Rural-urban migration in China: The past and present. In L. A. West \& Y. Zhao (Eds.), Chinese rural labor flows, pp. 15-33. Berkeley, CA: Institute for East. 